\title{
THE ASSAY ON GUINEA PIGS OF THE HEMATOPOIETIC ACTIVITY OF HUMAN LIVERS, NORMAL AND PERNICIOUS ANEMIA.", 2
}

\author{
BY BERNARD M. JACOBSON \\ (From the Medical Clinic, Massachusetts General Hospital, and the Department of Medicine \\ and Biochemical Laboratory of the Harvard Medical School, Boston)
}

(Received for publication May 15, 1935)

In the foregoing communication (1), it was pointed out that the indirect evidence for the validity of the assay on guinea pigs of liver extracts of their. therapeutic potency in pernicious anemia must rest upon a more crucial experimental basis than upon the fact that a moderately large number of various therapeutically inert materials are likewise inert in the guinea pig. As long as the material in liver, which exerts the therapeutic effect, remains unavailable in pure form for testing in the guinea pig, a different type of experiment must be resorted to. Such an experiment is suggested by the observations of Richter, Ivy, and Kim (2); of Goldhammer, Isaacs, and Sturgis (3), and of Wilkinson and Klein (4). The results of all of these observations are identical, and may be summarized as follows: (1) the extract of the liver of a patient dying of disease other than pernicious anemia is therapeutically effective in pernicious anemia; (2) the extract of the liver of a patient treated for pernicious anemia, but dying, while in partial remission, of other disease, is almost as effective as the normal liver in the treatment of pernicious anemia; (3) the extract of the liver of a patient dying in relapse of pernicious anemia is totally inert in the treatment of this disease.

\section{METHODS}

The livers of four patients were obtained, and were treated in an identical fashion. Each liver was finely ground, thoroughly mixed with an equal weight of 95 per cent alcohol, and dried on the steam bath about 20 hours. The resultant dry liver was reduced to a fine

1 This study was made possible by assistance from the William W. Wellington Research Fund and the DeLamar Mobile Research Fund of Harvard Medical School and by Therapeutic Research Grants Numbers 206 and 244 of the Council on Pharmacy and Chemistry of the American Medical Association.

2 Presented in abstract before the American Society for Clinical Investigation, April 30, 1934. powder. In order to secure an extract of the tissue which would contain practically all of the nonprotein nitrogenous substances, a crude extract was made by the Schenk method. To the powdered liver derived from 100 grams of fresh liver were added $100 \mathrm{cc}$. of normal hydrochloric acid and $100 \mathrm{cc}$. of a saturated solution of mercuric chloride. The extraction took place overnight in the refrigerator, the precipitated protein was then filtered off, and the filtrate decomposed by hydrogen sulfide. The total nitrogen content of the several Schenk filtrates varied from 400 to $450 \mathrm{mgm}$. per 100 grams of fresh liver.

\section{Pathologic material}

Patient Number 1. Age 62. Diagnoses: Arteriosclerotic heart disease, cerebral arteriosclerosis, obstructing prostate, acute urinary retention. The liver was obtained 24 hours postmortem, and weighed 1520 grams.

Patient Number 2. Age 76. Diagnoses: Pernicious anemia, lymphosarcoma, bilateral hydrothorax, generalized arteriosclerosis. The liver was obtained 36 hours postmortem, and weighed 1470 grams.

The patient first entered the hospital thirteen months before death complaining of weakness and of generalized glandular enlargement. A biopsy of a lymph node revealed the presence of lymphosarcoma. He was discharged following satisfactory treatment with deep roentgen radiation. Seven months before death, he re-entered the hospital complaining of recurrent attacks of sore tongue, gastro-intestinal disturbances, weakness, and paresthesias of the extremities. The physical examination revealed a lemon-yellow color of the skin and sclerae, Hunterian glossitis, generalized glandular enlargement, and impaired vibration sense in the lower extremities. The blood smear was typical of pernicious anemia; red blood cells 1,360,000, oxygen capacity 8.19 volumes per cent, cell volume 19.1 per cent, volume index 1.65 , color index 1.56. Achlorhydria after histamine. After the intramuscular administration of liver extract derived from 100 grams of fresh liver, the reticulocytes rose to 32 per cent on the sixth day, and the erythrocytes rose from $1,290,000$ to $2,070,000$ on the twelfth day. After continued liver therapy during the following three months, the erythrocytes rose to $4,670,000$, and the oxygen capacity to 15.5 volumes per cent. One month before death the patient re-entered the hospital because of recurrent glandular enlargement. Red blood cells 3,270,000 at time of entry, $3,350,000$ five days before death. During this period, the patient received, at intervals of three to five days, a total 
of nine intramuscular injections, each of liver extract derived from 100 grams of liver.

Patient Number 3. Age 76. Diagnoses: Pernicious anemia, pulmonary edema, acute cardiac failure, coronary sclerosis.

The liver was obtained 22 hours postmortem, and weighed 1530 grams.

The day before death the erythrocytes were $1,000,000$, oxygen capacity 5.25 volumes per cent. The patient received, intramuscularly, liver extract derived from 200 grams of liver three and one-half hours before death.

Patient Number 4. Age 66. Diagnoses: Pernicious anemia, arteriosclerotic heart disease, congestive heart failure, auricular fibrillation, bronchopneumonia. The liver was obtained 10 hours postmortem, and weighed 1460 grams.

Two days before death the erythrocytes numbered 800 ,000 , oxygen capacity 5.05 volumes per cent. During the 36 hours preceding death, the patient received by the intramuscular route, liver extract derived from 180 grams of liver; and the day before death a transfusion of 700 cc. of citrated blood.

The above four liver extracts were assayed in guinea pigs by the method described in the preceding communication (1). The protocols of these assays are presented in the accompanying table. It is evident that the livers of the patients dying of pernicious anemia contain only a negligible amount of reticulocytogenic material and that the liver of the patient dying in partial remission of pernicious anemia contains an appreciable quantity of such material, but far less than is contained in the non-pernicious anemia liver. These results are in harmony with the assays of similar livers on patients suffering from pernicious anemia (vide supra).

\section{SUM MARY}

Indirect evidence for the validity of the guinea pig method of assay of the therapeutic potency of liver extracts in pernicious anemia is furnished by the fact that crude extracts of human livers, when assayed in guinea pigs, yielded the following number of guinea pig units, per 100 grams of fresh liver: pernicious anemia in relapse, 650 and 348, respectively; pernicious anemia in partial remission, 47,000; non-pernicious anemia, 127,000 .

\section{BIBLIOGRAPHY}

1. Jacobson, B. M., The response of the guinea pig's reticulocytes to substances effective in pernicious anemia. A biologic assay of the therapeutic

TABLE I

A ssays of human livers

Patient number 1. Control subject

\begin{tabular}{|c|c|c|c|c|c|c|c|c|}
\hline 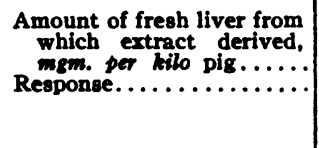 & $\begin{array}{c}1.08 \\
+++\end{array}$ & $\stackrel{0.86}{++}$ & $\begin{array}{c}0.79 \\
++-\end{array}$ & $\begin{array}{c}0.72 \\
\pm--\end{array}$ & $\begin{array}{c}0.61 \\
\pm--\end{array}$ & 0.54 & 0.48 & $\begin{aligned} & \text { Assay: } 100,000 \mathrm{mgm} . / 0.79 \mathrm{mgm} .=127,000 \\
& \text { G. P. U. per } 100 \text { grams fresh liver }\end{aligned}$ \\
\hline
\end{tabular}

Patient number 2. Pernicious anemia in remission

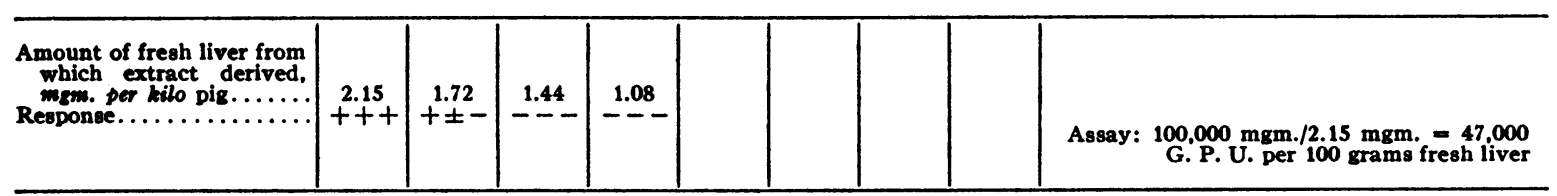

Patient number 3. Pernicious anemia in relapse

\begin{tabular}{|c|c|c|c|c|c|c|c|c|c|}
\hline 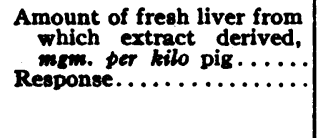 & $+4+$ & $\stackrel{215}{++}$ & +154 & +108 & -- & --- & $\stackrel{21.5}{---}$ & -15.4 & 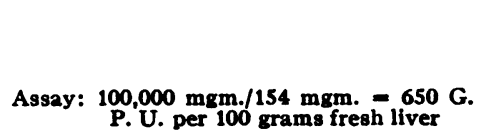 \\
\hline
\end{tabular}

Patient number 4. Pernicious anemia in relapse

\begin{tabular}{|c|c|c|c|c|c|c|c|c|}
\hline 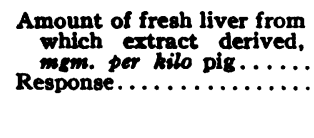 & $\begin{array}{c}430 \\
+t\end{array}$ & $\stackrel{287}{++ \pm}$ & +251 & 215 & $\stackrel{172}{--}$ & --- & --- & $\begin{array}{l}\text { Assay: } 100.000 \mathrm{mgm} . / 287 \mathrm{mgm} .=348 \mathrm{G} . \\
\text { P. U. per } 100 \mathrm{grams} \text { fresh liver }\end{array}$ \\
\hline
\end{tabular}


potency of liver extracts. J. Clin. Invest., 1935, 14,665 .

2. Richter, O., Ivy, A. C., and Kim, M. S., Action of human "pernicious anemia liver extract." Proc. Soc. Exper. Biol. and Med., 1932, 29, 1093.

3. Goldhammer, S. M., Isaacs, R., and Sturgis, C. C.,
The role of the liver in hematopoiesis. Am. J. M. Sc., 1934, 188, 193.

4. Wilkinson, J. F., and Klein, L., The hemopoietic activity of the normal and abnormal human liver, with special reference to pernicious anemia. Quart. J. Med., 1934, 3, 341. 